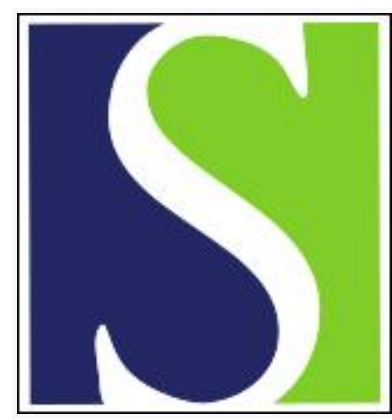

Scand J Work Environ Health 1984;10(6):373-380

https://doi.org/10.5271/sjweh.2305

Issue date: Dec 1984

On the interplay between socioeconomic factors, personality and work environment in the pathogenesis of cardiovascular disease.

by Theorell T, Alfredsson L, Knox S, Perski A, Svensson J, Waller D

This article in PubMed: www.ncbi.nlm.nih.gov/pubmed/6535241

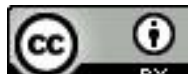




\title{
On the interplay between socioeconomic factors, personality and work environment in the pathogenesis of cardiovascular disease
}

\author{
by Töres Theorell, MD, ${ }^{1}$ Lars Alfredsson, DMedSc, ${ }^{2}$ Sarah Knox, PhD, ${ }^{3}$ Aleksander Perski, PhD, ${ }^{1}$ \\ Jan Svensson, $\mathrm{PhD},{ }^{1}$ Dick Waller, BSc ${ }^{1}$
}

\begin{abstract}
THEORELL T, ALFREDSSON L, KNOX S, PERSKI A, SVENSSON J, WALLER D. On the interplay between socioeconomic factors, personality and work environment in the pathogenesis of cardiovascular disease. Scand J Work Environ Health 10 (1984) 373-380. This article summarizes some of the major findings in research on associations between psychosocial factors and cardiovascular illness. Methodological difficulties are discussed. Findings from some of the authors' own studies serve as illustrations. It is emphasized that an interplay between environmental and individual factors is of great importance. Personality factors relevant to the risk of cardiovascular illness may distort individual descriptions of the work environment. Cardiovascular risk factors such as cigarette smoking and repeated blood pressure elevations may be influenced by psychosocial factors. Lack of intellectual discretion at work, particularly if combined with excessive demands, may increase the risk of cardiovascular illness.
\end{abstract}

Key terms: catecholamines, cigarette smoking, coronary heart disease, hypertension, monotony, psychosocial stress, social class.

Epidemiologic research has provided knowledge concerning differences in the incidence of cardiovascular illness between cultures, countries, and socioeconomic groups. In order to explain these differences, most cardiovascular epidemiologists have been interested in exploring the prevalence of accepted risk factors for cardiovascular illness (such as smoking and dietary habits). The aim has been to explore whether conventional risk factors could explain the differences in the incidence of cardiovascular illness between the same cultures, countries, and socioeconomic groups. Relatively few efforts have been devoted to describing psychosocial characteristics of different risk groups. Such characteristics could possibly explain the differences in cardiovascular illness incidence. Waldron and others (38), for instance, in their studies of blood pressure levels in different cultures, described a number of complex and interesting associations between type of economy, family patterns, dietary patterns, etc, on one hand and average blood pressure levels on the other. Marmot and others (75) described the Japanese people and their migration to the United States. These researchers

\footnotetext{
1 National Institute of Psychosocial Factors and Health, Stockholm, Sweden.

2 Department of Social Medicine, Huddinge Hospital, Huddinge, Sweden.

3 National Institute of Environmental Medicine, Stockholm, Sweden.
}

Reprint requests to: Prof T Theorell, National Institute of Psychosocial Factors and Health, Box 60210, S-104 01 Stockholm, Sweden. studied the extent to which those who moved adhered to specifically Japanese psychosocial living patterns or adopted more American styles. Those migrants who retained certain critical elements of the Japanese psychosocial life-style were observed to be protected to some extent against cardiovascular illness, even when they adopted the same dietary and smoking habits as native Americans.

Macrolevel research $(5,7)$ is characterized by the fact that whole countries, groups, or cultures are compared to one another and that individual characteristics of people within the studied samples are not taken into account. Another characteristic of these studies has been that official statistics for the areas, groups, or cultures have been utilized. When results from this kind of study are interpreted, one has to bear in mind that aggregated statistics could never be applied to individual subjects. Such statistics could only be used for planning public health policy. One advantage, however, is that most of the individual biological variance is eliminated, and therefore the researcher is able to study, with a bird's eye perspective, more complex societal phenomena and their possible effects on cardiovascular illness incidence. This situation enables the researcher to discover social processes that may be harmful to populations or groups within populations. The same may also be true of occupational risk factors. A detailed description of psychosocial and physical characteristics of different occupations with subsequent linkage to morbidity and mortality statistics may provide hypotheses which could be tested in studies of individuals. 


\section{Occupational characteristics and cardiovascular morbidity}

During the last 10 years a number of studies have been published which indicate that the upper social classes in the United States, Great Britain, and the Scandinavian countries have a low incidence of cardiovascular illness (39). It has been pointed out that one explanation for this phenomenon may be that subjects in the upper social classes smoke fewer cigarettes than those in other classes (26). In the Scandinavian countries blood pressure elevation and elevated serum cholesterol also seem to be less common in the upper social groups than among other people (14).

What about psychosocial stress? There has been a common conception among laymen and researchers that stress is more common in the upper social classes. Modern stress epidemiology would indicate rather that subjects in the upper social classes have less adverse psychosocial strain than other people. For instance, in surveys based upon questionnaires or interviews, people with a low educational level mostly report fewer life events during a given year. However, those events that occur to people in the lower social classes are more often threatening and negative $(6,24)$. The social network that serves as a buffering factor against the adverse effects of psychosocial strain has also been reported to be poorer on the average among people with a low educational level than among others (28). With regard to work conditions our own studies indicate that subjects in high status occupations frequently report that they feel intellectual stimulation from what they do at work and also that they more often feel that they can control what is going on in their own work situation, for instance, with regard to work schedule (1). Both of these factors (intellectual stimulation and possibilities to control) are reported in the psychophysiological literature as serving as buffering factors against the adverse effects of excessive psychological demands $(18,22)$. Frankenhaeuser and her co-workers have observed in their research that effort in combination with distress is associated with an elevated excretion of cortisol, as well as catecholamines (18). Long-standing elevation of the cortisol excretion, for instance, during several weeks or months, could probably increase the vulnerability of the myocardium and, in this way, facilitate the triggering of a myocardial infarction. Karasek et al (19) have summarized these thoughts in a hypothesis formulation. In this system, occupations which frequently give rise to excessive psychological demands and at the same time offer low decision latitude and little intellectual discretion are labeled strain occupations. If this psychophysiologically based hypothesis is correct, myocardial infarction should be more common in occupations belonging to the strain group.

In Sweden we have been able to study occupations in two different register studies testing the Karasek hypothesis $(1,3)$. Table 1 summarizes the results of the studies, the first one based upon 334 cases and 882 referents and the second based upon a population of almost one million men and women.

Figure 1 shows the relative risk (age-standardized relative risk and $90 \%$ confidence intervals) of developing myocardial infarction, determined in the Huddinge study, among those working in an occupation in which many subjects reported that the work was hectic and did not give any possibility to learn new things in comparison to other occupations (2). The classification was based upon national surveys. For instance, those 59 out of 118 occupations with the largest proportion of subjects reporting "Yes my work is hectic" were labeled hectic occupations according to the national survey in 1977 . The casereferent sample that was utilized for calculating the relative risk was derived from hospitalization and mortality registers within one region of the Stockholm county for a three-year period. Every man between the ages of 40 and 64 years who developed a myocardial infarction (surviving or dying) was labeled a case. The reference sample was randomly selected from the same residential areas. Official

Table 1. Results a of two Swedish studies based on register data on 334 cases and 882 referents [the Huddinge study (2)] and another population of almost one million men and women [the five-counties study (3)]. Occupational characteristics derived from the 1977 survey of living conditions (National Bureau of Statistics).

\begin{tabular}{|c|c|c|c|c|c|}
\hline \multirow{3}{*}{ Occupational characteristics } & \multirow{2}{*}{\multicolumn{2}{|c|}{$\begin{array}{c}\begin{array}{c}\text { Relative risks } \\
\text { Huddinge study } \\
\text { Hudding }\end{array} \\
\text { Men }\end{array}$}} & \multicolumn{3}{|c|}{$\begin{array}{l}\text { Standardized morbidity ratios } b, c \text { in the } \\
\text { five-counties study }\end{array}$} \\
\hline & & & \multicolumn{2}{|c|}{ Men } & \multirow{2}{*}{$\begin{array}{c}\text { Women } \\
\text { Aged } \\
20-64 \\
\text { years }\end{array}$} \\
\hline & $\begin{array}{l}\text { Aged } \\
40-64 \\
\text { years }\end{array}$ & $\begin{array}{c}\text { Aged } \\
40-54 \\
\text { years }\end{array}$ & $\begin{array}{c}\text { Aged } \\
20-64 \\
\text { years }\end{array}$ & $\begin{array}{c}\text { Aged } \\
20-54 \\
\text { years }\end{array}$ & \\
\hline $\begin{array}{l}\text { Hectic and no possibilities to } \\
\text { learn new things }\end{array}$ & 1.5 & 2.3 & 128 & 157 & - \\
\hline Hectic and monotonous & - & 2.3 & 118 & 153 & 164 \\
\hline Hectic and heavy lifting & 1.4 & 2.4 & - & 145 & - \\
\hline
\end{tabular}

a Only significant numbers $(p<0.05)$ are shown.

b Age-adjusted.

c The standardized morbidity ratios have been tested for possible confounding. 

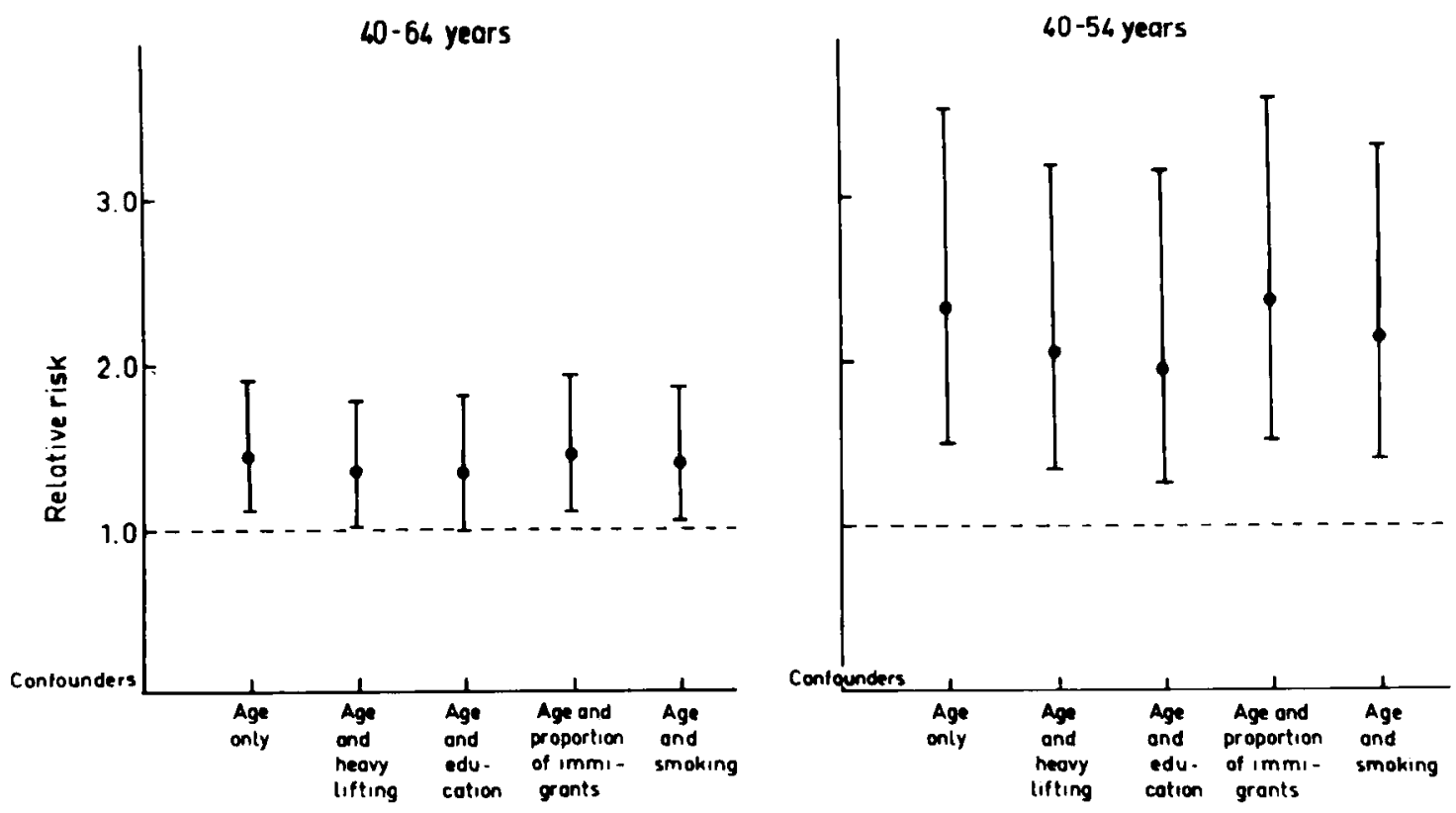

Figure 1. Relative risk of myocardial infarction and $90 \%$ confidence intervals of men in occupations characterized as hectic and with few possibilities to learn new things compared to men in other occupations - A case-referent study based on registers of mortality and morbidity (334 cases and 882 referents) (4).

statistics were utilized in order to find the three-digit occupational title of each individual. These occupational titles were then characterized by means of the used classification system. Analyses of relative risks and their statistical significances indicated that the most damaging combination for men was an occupation in which many subjects reported a hectic tempo and few possibilities to learn new things. This association was true even when the proportion of smokers, immigrants, subjects with a low level of education, and subjects reporting frequent heavy lifting was taken into account in the different occupations (1).

In the other register study, based on the populations of five counties (3), it was found that men working in occupations with frequent reports of hectic tempo and lack of possibilities to learn new things had an elevated risk of hospitalization for myocardial infarction and that this occupational risk factor had the strongest predictive power out of several studied possible occupational risk factors for men. Women were also studied. For them the combination "hectic and monotonous work" showed the strongest association with risk of being hospitalized for myocardial infarction. In table 1 only those associations are presented which hold even when possible confounders have been taken account of, such as marital status, type of residential area, full-time or part-time work, employed or self-employed work status, proportion of cigarette smokers, and proportion of subjects reporting frequent heavy lifting.

Thus, from these Swedish studies, we have consistent evidence that the Karasek hypothesis can be veri- fied. However, there may be pitfalls. For instance there may be spurious associations if any one of the following three conditions prove to be true: (i) if men or women with a behavior pattern associated with myocardial infarction "select themselves into" occupations labeled strain occupations in the Karasek system, (ii) if there is an influx of subjects with deteriorating cardiovascular health into the strain occupations, and (iii) if, with regard to smoking and diet and other relevant life-style factors, there is a higher prevalence of risk behavior in the strain occupations and this could occur without association to the work itself.

Not many studies have been published which explore the self-selection hypothesis. Type A behavior, which has been observed to correlate with risk of myocardial infarction among middle-aged men (29), has been studied with a modified Swedish version of the Jenkins activity survey (35) in a small-scale investigation of 28-year-old men whose initital work career was studied. Choice of type of occupation was not associated with these measures of type A behavior. Some of the neurotic personality traits that correlate with the type A behavior pattern did not correlate with vocational preference in an American population study (8). In that study vocational preference was correlated with extraversion. However extraversion has no simple association with risk of myocardial infarction (9). Subjects with pronounced type A behavior have been reported to dislike lack of control, and therefore it could be speculated that these subjects would rather avoid occupations with a low degree of decision latitude. So far, nothing speaks in 
favor of the hypothesis that the association between working in a strain occupation and elevated risk of myocardial infarction would be due to self-selection.

The second argument is also difficult to explore. However it would be more likely that subjects who have had a previous myocardial infarction or other symptoms of cardiovascular illness and thus run a greater risk in the near future of having a myocardial infarction would avoid hectic work situations. This probability would lead rather to underestimations of associations in our studies.

As for the third possibility, it might be that subjects in some of the low-status occupations may have been taught the wrong diet and other health damaging behavior during childhood. We have observed that 18-year-old men who have grown up in areas of Stockholm where many families have a low income and where the number of persons on social welfare is high have a higher relative weight and a higher systolic blood pressure than men of the same age growing up in other areas (37). However it is unlikely that this occurrence explains all of the association between working in a strain occupation and elevated risk of myocardial infarction. Karasek and others have made a cross-sectional study (20) using a job title inference system similar to ours. In this investigation the prevalence of clinical evidence of a past myocardial infarction was studied both in relation to psychosocial occupational characteristics and in relation to clinical individual characteristics. High strain occupations were again observed to have an elevated prevalence of a past myocardial infarction (table 2), and this relation was true even when individual blood pressure, smoking habits, and serum cholesterol levels were taken into account.

The main conclusion to be drawn from the preceding discussion seems to be that type of occupation has some association with risk of myocardial infarction even if people select and change occupations. However, we need more knowledge about this association - about the relation between time of exposure to certain types of occupations and risk of cardiovascular illness, about whether the association is due to the fact that subacute strain situations, ie, strain situations lasting for weeks and months, may be more common in risk occupations or whether

Table 2. Evidence of past myocardial infarction in relation to psychosocial occupational characteristics - Independent contributions (multiple logistic regression) $(\mathrm{N}=2190)(20)$.

\begin{tabular}{lcc}
\hline Occupational characteristic & $\begin{array}{c}\text { Standardized } \\
\text { risk ratio }\end{array}$ & $\mathrm{p}$-Value \\
\hline Decision latitude & -1.81 & 0.003 \\
Psychological demands & 1.85 & 0.022 \\
Physical strain & -1.85 & 0.002 \\
\hline
\end{tabular}

a After control for covariance with age, education, systolic blood pressure, and smoking. there are also associations between type of occupation and coronary atherosclèrosis, and about whether the associations are due to the fact that some occupations are strainful in a way which increases the need for cigarette smoking or wrong dietary habits or whether the associations are due to psychophysiological mechanisms.

Even in a psychosocial context there remains some insecurity. The researcher who makes direct questions to subjects under study should be aware that it may not be those individuals who report that they suffer from excessive demands and a low decision latitude that are more likely to become seriously ill in the long run. We know from numerous studies that there are correlations between self-reported somatic symptoms and adverse work environments. However, when physiological, serious, long-term disturbances are being studied, it could be that subjects who deny problems or show overly optimistic attitudes towards adverse work structures are more likely than other subjects to develop serious illness in the long run. Finnish studies of policemen have shown that those policemen who show the most overly optimistic attitudes may run a greater risk of sudden cardiac death (27). In modern work psychology many researchers are trying to develop collective measures of the psychosocial atmosphere of a workplace in order to cope with this kind of difficulty.

Recently we have preformed a study in collaboration with the medical department of the Danderyd Hospital. This study has not as yet been reported. Some preliminary findings are available however. All male victims of myocardial infarction before the age of 45 years during a given time period in the Stockholm area were asked to participate in this study. Subjects who had died after the infarction were of course not included since this investigation was a retrospective interview study exploring the individual's own perception of the work situation before the infarction. The comparison sample was an agematched group of men living in the same area. Again combinations of psychologically demanding and monotonous work situations, as well as psychologically demanding work situations with few opportunities to learn new things, were significantly more often reported in the infarction group than in the reference group. There were 58 and 100 subjects in the case and reference groups, respectively. The analyses indicated that the magnitude of these associations was roughly equal to those observed for men under 54 years of age in the register studies (de Faire, Hamsten, Theorell, Orth-Gomér, Perski, personal communication). It is difficult to draw any conclusions concerning the source of error introduced by the individuals' own bias, since this sample was younger and since this study had a retrospective design. However, the fact that there was again a significant association speaks in favor of the opinion that we are dealing with a strong association. 
From macrolevel to microlevel research and from late-stage cardiovascular disease to its early stage

One possible mechanism behind the association between psychosocial factors and risk of myocardial infarction may be frequent and long-lasting elevations of blood pressure. In order to explore this possibility, we have made a follow-up study of 26- to 32 -year-old men in the beginning of their work career. All these men had been subjected to medical examinations during military recruitment at the age of 18. This recruitment is compulsory, and therefore we were able to select from the total population of 18-year-old men in the county of Stockholm those who were recruited during a certain period and who had had a blood pressure of at least $146 \mathrm{~mm} \mathrm{Hg}$ $(19465 \mathrm{~Pa})$ systolic and at the same time at least $90 \mathrm{~mm} \mathrm{Hg}(11999 \mathrm{~Pa})$ diastolic after $10 \mathrm{~min}$ of rest in the supine position on two separate occasions. There were 75 such subjects. A random sample was selected $(\mathbf{N}=31)$ from those who were recruited during the same period and who had a systolic blood pressure of $126-130 \mathrm{~mm} \mathrm{Hg}(16799-17331 \mathrm{~Pa})$. Furthermore one other random sample $(\mathrm{N}=31)$ among those with a low blood pressure [systolic 100$106 \mathrm{~mm} \mathrm{Hg}(13332-14132 \mathrm{~Pa})]$ was selected. Of the original groups $75(\mathrm{~N}=56), 87(\mathrm{~N}=27)$, and 74 $(\mathrm{N}=23) \%$, respectively, were examined with regard to blood pressure after 10 years. Rather extensive examinations were performed comprising blood tests and self-measurements of blood pressure once an hour during an ordinary workday, as well as psychological interviews. The participation rate was between 60 and $75 \%$ of all eligible subjects. Medication for hypertension was taken by seven persons. No subject included in this study had secondary hypertension or advanced secondary damage due to hypertension. The nonparticipants did not differ from the participants with regard to type of occupation. A high resting blood pressure level - diastolic pressure of at least $90 \mathrm{~mm} \mathrm{Hg}(11999 \mathrm{~Pa})$ and at the same time a mean arterial pressure (diastolic plus one-third of the difference between systolic and diastolic) equal to at least $110 \mathrm{~mm} \mathrm{Hg}(14665 \mathrm{~Pa})$ after $1 \mathrm{~h}$ of rest in the supine position - was observed among 41,8 , and $0 \%$ of the original groups (high, normal, and low, respectively).

Plasma adrenaline was measured after $1 \mathrm{~h}$ at rest in the supine position (13). Plasma renin activity was measured during activity [New England Nuclear, angiotension I $(125 \mathrm{I})$ radioimmunoassay kit]. The personality inventory that was used was the one introduced by Schalling and co-workers at the Karolinska Hospital (33). Blood pressure measurements were performed at the hospital with or without preceding rest. Furthermore, blood pressure was measured by the subject himself once an hour during a workday during normal activities. According to these measurements subjects were divided into those who had a high blood pressure at rest, those who had a high blood pressure according to the criterion already presented at least once during activity, and finally those who had normal blood pressure on all measurement occasions.

The group with the high blood pressure at rest had a significantly higher body weight than the other subjects. The group with normal blood pressure on all occasions had significantly lower plasma adrenaline than the other subjects. Persons in the group with a high blood pressure at rest described themselves as less verbally aggressive than the others. On the basis of a more thorough interview during which a psychologist without knowledge of the blood pressure level of the person in question explored the person's ability to identify the feelings anger, sorrow, joy, and anxiety, it was shown that those variables which differentiated between these groups the most efficiently were ability to describe sorrow and the frequency of the feeling of joy. Thus the subjects with high blood pressure at rest were less able to describe sorrow and also less frequently felt that they were joyful. However the subjects in the three groups were equally able, on the average, to describe anger.

We believe that the interpretation of the environment is a research field which needs much more consideration in future studies. For some reason, researchers in this field have concentrated almost entirely on the feeling of anger aroused by the environment. It is quite possible that other feelings are more important. In the psychosomatic field the "alexithymia concept" has been introduced. Alexithymia denotes inability to describe verbally feelings that are being aroused. It is possible that subjects who cannot differentiate between feelings and analyze them properly would be vulnerable to adverse work conditions. In these cases both the environment and the individual's ability to handle these situations would have to be addressed.

We also analyzed, by means of a questionnaire modified after Henderson et al (12), the individual's own reported social network. Men with high blood pressure at rest more frequently reported a poor social network (figure 2).

Type of occupation and occupational career during the first years did not differentiate the groups from one another. However, individuals with a high blood pressure at the age of 18 - thus subjects with an early manifested propensity to react with blood pressure elevations - who were now working in occupations classified in the classification system as hectic and not controllable (such as waiter, driver, cook) showed a more pronounced elevation in blood pressure than other subjects during their work as compared to during their leisure time (table 3 ). There was a statistically significant three-way interaction between blood pressure at the age of 18 years, type of occupation, and time of measurement (during or 
Table 3. Average systolic blood pressure outside work (seven measurements/subject) and during work (seven measurements/ subject) - Measurements at 28 years of age in relation to type of present occupation (strain = hectic and uncontrollable with regard to work tempo) and blood pressure at the age of $18(36)$. (Three-way interaction $p=0.03$ ).

\begin{tabular}{|c|c|c|c|c|}
\hline & \multicolumn{2}{|c|}{$\begin{array}{l}\text { Low or medium blood } \\
\text { pressure at age } 18\end{array}$} & \multicolumn{2}{|c|}{$\begin{array}{l}\text { High blood pressure at age } \\
18(\geq 146 \text { and } \geq 90 \mathrm{~mm} \mathrm{Hg})\end{array}$} \\
\hline & $\begin{array}{c}\text { Other } \\
\text { occupations } \\
N=28\end{array}$ & $\begin{array}{c}\text { Strain } \\
\text { occupations } \\
N=13\end{array}$ & $\begin{array}{c}\text { Other } \\
\text { occupations } \\
\mathbf{N}=23\end{array}$ & $\begin{array}{c}\text { Strain } \\
\text { occupations } \\
N=7\end{array}$ \\
\hline $\begin{array}{l}\text { Systolic blood pressure outside work } \\
\text { Systolic blood pressure during work }\end{array}$ & $\begin{array}{l}122 \\
125\end{array}$ & $\begin{array}{l}124 \\
126\end{array}$ & $\begin{array}{l}136 \\
144\end{array}$ & $\begin{array}{l}135 \\
153\end{array}$ \\
\hline
\end{tabular}

a $1 \mathrm{~mm} \mathrm{Hg} \approx 133.332 \mathrm{~Pa}$.

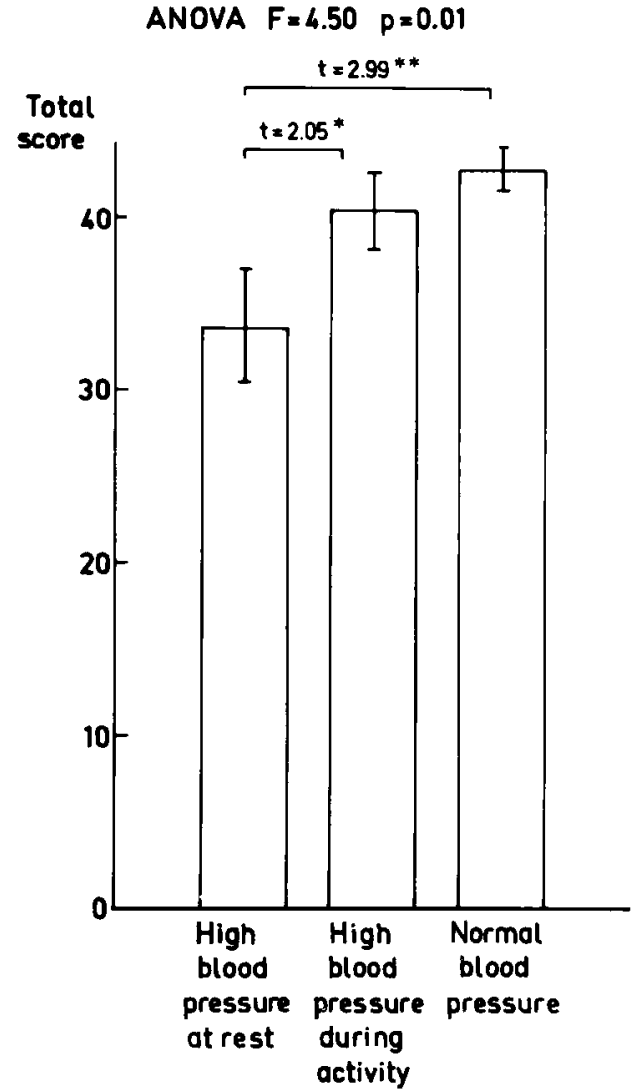

Figure 2. Social support received by men (self-repurts) in a study (36) of the relation between psychosocial factors and high blood pressure - Means and standard errors of the means.

outside work) in the effect on recorded blood pressure level.

All the subjects were asked the very simple question: "Why does one work?" They answered in their own words. An independent person later grouped the answers. Table 4 shows the results. The men in the group with high blood pressure at rest more frequently reported psychological motives for working than other men. Earlier studies on representative groups of young people have shown that a high motivation for performance is correlated with a high blood pressure at rest (31). The group with the high blood pressure during activity very frequently reported physical
Table 4. "Blind" rating of open answers to the question "Why do people work?" in a study on the relation between psychosocial factors and blood pressure.

\begin{tabular}{lccc}
\hline & $\begin{array}{c}\text { Men with } \\
\text { high } \\
\text { blood } \\
\text { pressure } \\
\text { at rest }\end{array}$ & $\begin{array}{c}\text { Men with } \\
\text { high } \\
\text { blood } \\
\text { pressure } \\
\text { during } \\
\text { activity }\end{array}$ & $\begin{array}{c}\text { Men with } \\
\text { normal } \\
\text { blood } \\
\text { pressure }\end{array}$ \\
\hline $\begin{array}{l}\text { Because it is psycholog- } \\
\text { ically necessary }\end{array}$ & 11 & & \\
Other reasons & 11 & 17 & 31 \\
\hline
\end{tabular}

$x^{2}=6.03, p<0.05$.

work environment problems (35). After factor analysis we were able to test a small number of hypotheses regarding the work environment in relation to blood pressure at rest. A surprising finding was that systolic, as well as diastolic, blood pressure at rest was associated with a high total score of work satisfaction. Even the variable increase in blood pressure at work compared to outside work was associated with a high degree of work satisfaction. We believe that these findings reflect the fact that subjects with a low degree of aggression and a high degree of work motivation would tend to distort their work description and give too favorable a view of their own work. This is a serious source of error in all studies of blood pressure at rest and thus also in studies of the pathogenesis of primary hypertension (21).

A multivariate analysis of personality inventories using standardized questionnaires showed that a high score for type A behavior [Swedish version of Jenkin's activity survey $(16,23)]$ and a high score of socialization (33) were associated with high systolic blood pressure during work (but not outside work and not at rest). Again this association was true only for those men who had had a high blood pressure at the age of 18. This observation is in accordance with previous observations indicating that type $\mathrm{A}$ behavior, which is a response pattern evoked by certain environmental conditions, is associated only with blood pressure during activity, not at rest (32). It also emphasizes that several associations (relevant to the later development of myocardial infarction) between psychosocial factors and blood pressure variations in young men are true only among those who have high 
blood pressure at rest at a young age. This finding demonstrates the significance of interaction between the psychosocial environment and the psychophysiological propensity to react.

A high degree of socialization and a low degree of self-perceived aggression in relation to the environment (despite a normal ability to describe aggression), a low frequency of joy, high performance motivation, and high work satisfaction were associated with high blood pressure at rest in young Swedish men. It is possible that the personality of subjects in this group is associated with a distorted description - too positive a picture - of the work situation. Therefore it may be dangerous to rely on self-administered work descriptive questionnaires with this group. That persons with high blood pressure at rest tend to underreport bodily complaints has been shown by Tibblin \& Lindström (34). Despite the fact that some studies have concluded that young persons with an early stage of essential hypertension report less aggression to the environment than other persons, other authors have observed that feelings of hostility may be more common among young borderline hypertensives than among other people (17).

There are several ways of developing hypertension. It is probably difficult to observe meaningful associations between psychosocial factors and essential hypertension if all kinds of essential hypertension are grouped together. Overweight, alcohol consumption, and sympathoadrenomedullary activation $(10,11$, 17,30 ) all seemed to be important to the development of hypertension in our study, as well as in other studies. Each one of these factors has different psychosocial correlates.

Blood pressure elevations during work have psychosocial correlates similar to those for middle-aged men who have an elevated risk of myocardial infarction. The psychosocial correlates of high blood pressure at rest are, on the other hand, quite different for young persons. Possibly more studies should be carried out on blood pressure variations during work in order to arrive at an improved understanding of the complex associations between psychosocial factors and cardiovascular illness (15).

\section{References}

1. Alfredsson L. Myocardial infarction and environment: Use of registers in epidemiology. Department of Social Medicine, Huddinge Hospital, Karolinska Institute, Stockholm 1983. (Doctoral dissertation).

2. Alfredsson L, Karasek RA, Theorell T. Myociardial infarction risk and psychosocial work environment: An analysis of the male Swedish working force. Soc Sci Med 16 (1982) 463-467.

3. Alfredsson L, Spetz C-L, Theorell T. Type of occupation and near-future hospitalization for myocardial infarction and some other diagnoses. Int J Epidemiol (in press).

4. Alfredsson L, Theorell T. Job characteristics of occupations and myocardial infarction risk: Effects of pos- sible confounding factors. Soc Sci Med 17 (1983) 1497-1503.

5. Brenner $\mathbf{M H}$. Mortality and the national economy: $\mathbf{A}$ review, and the experience of England and Wales 1936-76. Lancet 2 (1979) 568-573.

6. Brown GW, Harris T. Social origins of depression - A study of psychiatric disorder in women. Tavistack, London 1978.

7. Bruhn J, Wolf S. An anatomy of health: The Roseto story. University of Oklahoma Press, Oklahoma City, OK 1978

8. Costa PT, McCrae RR. Personality and vocational interests in an adult sample. J Applied Psychol (in press).

9. Flodérus B. Psycho-social factors in relation to coronary heart disease and associated risk factors. Nord Hyg Tidsk (1974): suppl 6, $148 \mathrm{p}$

10. Folkow B. Physiological aspects of primary hypertension. Physiol Rev 62 (1982) 347-504.

11. Harlan WR, Cornoni-Huntley J, Leverton PE. Blood pressure in childhood - The national health examination survey. Hypertension 1 (1979) 559.

12. Henderson S, Byrne DG, Duncan-Jones P. Neurosis and the social environment. Academic Press, Sydney 1982.

13. Hjemdahl P, Daleskog M, Kahan T. Determination of plasma catecholamines by high performance liquid chromatography with electro-chemical detection: Comparison with a radio-enzymatic method. Life Sci 25 (1979) 131.

14. Holme I, Helgeland A, Hjermann I, Leren P, LundLarsen PG. Coronary risk factors in various occupational groups: The Oslo study 1977. Br J Prev Soc Med 31 (1977): 2, 96-100.

15. Jason M, Devereux R, Harshfield GA, Kleinert HD, Pickering TG. Blood pressure variability in hypertension: Are psychological factors important? Circulation 66 (1982): suppl II. (Abstract no 144).

16. Jenkins CD, Zyzanski SJ, Rosenman RH. Progress toward validation of a computer-scored test for the type A coronary-prone behaviour pattern. Psychosom Med 33 (1971) 193.

17. Jern S. Psychological and hemodynamic factors in borderline hypertension. Acta Med Scand Suppl 662 (1982) $1-54$.

18. Johansson $G$. Individual control in a repetitive task: Effects on performance, effort and physiological arousal. Department of Psychology, University of Stockholm, Stockholm 1982. (Report no 579)

19. Karasek RA, Russel RS, Theorell T. Physiology of stress and regeneration in job related cardiovascular illness. J Hum Stress 8 (1982) 29.

20. Karasek RA, Schwartz J, Theorell T. Job characteristics, occupation and coronary heart disease. Department of Industrial Engineering and Operations Research, University of Columbia, New York, NY 1982.

21. Knox S, Theorell T, Svensson J, Waller D. Subjective description and "objective" classification of jobs in relation to blood pressure level and blood pressure variations. In: Proceedings of the Third International Conference on System Science in Health Care, 16-20 July, 1984, Springer, Munich 1984, pp 280-285.

22. La Rocco JM, House JS, French JRP. Social support, occupational stress and health. J Health Soc Behav 21 (1980) 202

23. Lundberg U. Type A behaviour and psychophysiological arousal. Scand J Psychol 23 (1982): suppl 1, 145-150.

24. Markush RE, Favero RV. Epidemiologic assessment of stressful life events, depressed mood and psychophysiological symptoms - A preliminary report. In: Dohrenwend BS, Dohrenwend BP, ed. Stressful life events: Their nature and effects. Wiley and Sons, New York, NY 1974, pp 171-190.

25. Marmot MG. Stress, social and cultural variations in 
heart disease. J Psychosom Res 27 (1983) 377-384.

26. Marmot MG, Rose G, Shipley M, Hamilton PJS. Employment grade and coronary heart disease in British civil servants. J Epidemiol Community Health 32 (1978) $241-249$.

27. Nirkko O, Lauroma $M$, Siltanen $P$, Tuominen $H$, Vankala K. Psychological risk factors related to coronary heart disease: Prospective studies among policemen in Helsinki. Acta Med Scand Suppl 660 (1982) 137.

28. Orth-Gomér K, Wallin B-M, Undén A-L. Social support and risk factors for ischemic heart disease. National Institute for Psychosocial Factors and Health, Stockholm 1984.

29. Rosenman RH, Brand R, Jenkins CD, Friedman M, Straus R, Wurm $M$. Coronary heart disease in the WCGS: Final follow-up experience of $81 / 2$ years. J Am Med Assoc 233 (1975) 872-877.

30. Saunders GB, Beevers DG, Paton A. Alcohol-induced hypertension. Lancet 2 (1981) 653 .

31. Shekelle RE, Harburg E, O'Malley PO, Miller RA. Psychological factors and high blood pressure in adolescents. In: Lauer RM, Shekelle RE, ed. Childhood prevention and hypertension. Raven Press, New York, NY 1980.

32. Siegel JM, Matthews KA, Leitch CJ. Blood pressure variability and the type $A$ behavior pattern in adolescence. J Psychosom Res 27 (1983) 265-272.

33. Schalling D, Cronholm B, Åhsberg M. Components of state and trait anxiety as related to personality and arousal. In: Levi $L$, ed. Parameters of emotion. Raven Press, New York, NY 1974, pp 603-617.
34. Tibblin G, Lindström B. Complaints in subjects with angina pectoris and hypertension. In: Zanchetti $\mathrm{A}$, ed. Neural and psychological mechanisms in cardiovascular disease. "Il ponte," Milan 1972.

35. Theorell T, Knox S, Svensson J, Waller D. Arbete och blodtryck: En tio-års-uppfölning av tri kontrastgrupper (högt, normalt och lågt blodtryck) från de medicinska värnpliktsundersökningarna vid 18 års ålder [Work and blood pressure: A ten-year follow-up of three contrast groups (high, normal and low blood pressure) from the medical examinations when drafting at the age of 18]. National Institute for Psychosocial Factors and Health, Laboratory for Clinical Stress Research, Stockholm 1983. (Stress research reports no 166).

36. Theorell T, Knox S, Svensson J, Waller D. Blood pressure variations during a working day at age 28 - Effects of different types of work and blood pressure at age 18. J Hum Stress (in press).

37. Theorell T, Svensson J, Knox S, Ahlborg B. Blood pressure variations across areas in the greater Stockholm region: Analysis of 74,000 18-year-old men. Soc Sci Med 16 (1982) 469-473.

38. Waldron I, Nowotarski M, Freimer M, Henry JP, Post $\mathrm{N}$, Witten $\mathrm{C}$. Cross-cultural variations in blood pressure - A quantitative analysis of the relationships of blood pressure of cultural characteristics, salt consumption and body weight. Soc Sci Med 16 (1982) 419-430.

39. —. Ohälsa och vårdutngttjande [Poor health and utilization of care]. In: Liber. Hälso- och sjukvård in för 90-talet. Stockholm 1981, pp 31-300. (SOU 1981:2). 